Original Research Article

\title{
Assessment of knowledge, attitude and practices among the residents and interns about rational fixed drug combinations in tertiary health care centre in Central India
}

\author{
Pallavi Admane*, Sachin Hiware, Mohini Mahatme, Sujata Dudhgaonkar, \\ Mukunda Bargade, Swapnil Deshmukh
}

Department of Pharmacology, Indira Gandhi Government Medical College, Nagpur, Maharashtra, India

Received: 30 May 2017

Revised: 17 July 2017

Accepted: 24 July 2017

*Correspondence to:

Dr. Pallavi Admane,

Email: admanester@gmail.com

Copyright: () the author(s), publisher and licensee Medip Academy. This is an openaccess article distributed under the terms of the Creative Commons Attribution NonCommercial License, which permits unrestricted noncommercial use, distribution, and reproduction in any medium, provided the original work is properly cited.

\begin{abstract}
Background: Fixed drug combination (FDC) is a combination of two or more active drugs in a single dosage form. Rational fixed drug combination improves patient compliance, enhances the efficacy of combination and minimizes side effects. But unfortunately, many FDCs introduced in Indian market are irrational. Prescription of irrational FDCs increases morbidity, mortality, treatment failure, emergence of resistance and financial loss to community. Since junior doctors like residents and interns are the backbone in patient care in the tertiary care hospital, knowledge of FDC in them has paramount importance.

Methods: A prospective, cross sectional, observational study was carried out to assess the knowledge, attitude and practice about the use of FDC by junior resident doctors and interns. A pre-validated questionnaire was given to two hundred doctors from various departments and data was analyzed. Questions were based on knowledge of National Essential List of Medicine (NELM), rational FDC and criteria of rationality.

Results: Seventy six percent health care professionals had the knowledge of FDC. Only $48 \%$ were aware about FDCs mentioned in WHO Essential List of Medicine. Most of them were aware of advantages and disadvantages of FDCs. Common sources of information were medical representatives, textbooks and Current Index Of medical Specialities (CIMS). Fifty eight percent doctors preferred to prescribe FDC, and ninety two percent avoid use of irrational FDCs. Most commonly prescribed rational fixed drug combination was amoxicillin + clavulanic acid. Paracetamol + ibuprofen was the most commonly prescribed irrational FDC.

Conclusions: There is need to improve knowledge of rational fixed drug combination, NELM list.
\end{abstract}

Keywords: ADR, FDC, NELM

\section{INTRODUCTION}

The Food and Drug Administration, USA defines a combination product as 'a product composed of any combination of a drug and a device or a biological product and a device or a drug and a biological product or a drug, device, and a biological product.' ${ }^{1}$ Fixed Dose Combination (FDC) is a combination of two or more active ingredients in a fixed ratio of doses. The combination products are acceptable only when the dosage of each ingredient meets the requirement of a defined population group and has a proven advantage over single compound administered separately in therapeutic effect, safety or compliance. FDCs enhance the efficacy of individual drugs, decrease the chances of drug resistance (e.g. antimicrobial drugs), decrease the pill burden and finally improve the patient compliance. There are only 27 approved FDCs according to the nineteenth WHO Model Essential Medicines List. ${ }^{2}$

FDCs are highly popular in the Indian pharmaceutical market and have been particularly flourishing in the last 
few years. However, there are some disadvantages associated with the use of FDCs like irrational prescription of FDCs, ineffective and unsafe treatment, difficulty in titration of dose of medicine to suit individual patients, identification of the drug causing adverse drug effect, exacerbation or prolongation of illness and higher treatment cost. $^{3}$ Poor knowledge, inappropriate, indiscriminate use of FDCs may lead to prescription of irrational FDCs which may lead to unsafe and ineffective treatment, increased cost and unnecessary exposure of drug and adverse drug reactions (ADR).

There is seven point criteria for rationality of FDC which is based on mechanism of action, drug interaction, efficacy, safety and cost. ${ }^{4}$ Awareness of rational FDC among the health care Professionals is very important to avoid overuse of irrational FDC.

Therefore, this study was conducted to assess awareness of rational FDCs among resident doctors and interns in an Indian tertiary care teaching hospital.

Aim of the study was to evaluate knowledge, attitude and practice regarding rational FDCs among the resident doctors and interns at tertiary care teaching hospital.

\section{METHODS}

\section{Study design}

This study was a cross-sectional, questionnaire based survey which was undertaken in a teaching hospital in Central India conducted between June 2015 and August 2015.

\section{Sample size}

A total of 200 resident doctors and interns participated voluntarily in the study and filled the given questionnaire.

\section{Study procedure}

Junior resident doctors and interns working in medicine, surgery, paediatrics, obstetrics gynaecology and dermatology departments of a tertiary care hospital in central India, were enrolled in the study after obtaining an informed consent. The participants were briefed about the nature and purpose of the study before subjecting to the questionnaire. Those who were not willing to participate or did not return the questionnaire within the stipulated time were excluded. Each participant was allotted 20 minutes to answer the questionnaire.

The pre-validated questionnaire comprised of 16 questions. The completed questionnaire was evaluated, analysed and frequency was expressed as percentage. Prescription audit was done to assess the use of rational FDC. Prescriptions were collected from various departments in the institute.

\section{RESULTS}

Among 200 doctors participated in the study, 128 were junior residents and 72 interns. The study was conducted to assess the information about the knowledge, attitudes and the practices of rational FDCs.

Table 1 shows the knowledge of FDC among doctors. 76\% subjects were aware of the concept of FDC, 56\% doctors had the knowledge of total number of drugs in NELM and $48 \%$ knew the total numbers FDC in WHO essential list of medicine. Most of them were aware of advantages of FDC.

Among the advantages mentioned improvement of patient compliance $(78 \%)$ was the major advantage and inability to adjust the dose $(46 \%)$ was the major disadvantage enlisted by all. Only $23 \%$ doctors were able to mention the complete criteria of rationality. Fifty eight percent of them were able to retrieve banned drug in India. CIIMS was the most preferred source of information referred by $49 \%$ doctors.

Table 2 depicts the assessment of questionnaire based on attitude regarding FDC. Fifty eight percent (58\%) of the doctors preferred to prescribe FDC. Ninety two percent $(92 \%)$ doctors thought that they could avoid use of irrational FDC, and $89 \%$ doctor thought prescribing irrational FDC can cause ADRs. Only $12 \%$ thought that rational FDC can cause ADRs. Forty three percent (43\%) read article on FDC. Ninety three percent $(93 \%)$ doctors provided direction regarding use of FDC. Ninety one percent $(91 \%)$ doctors were aware of rationality or irrationality before prescribing FDC.

Only $464(23.45 \%)$ of 1978 collected prescriptions contained FDCs. Figure 1 show that antimicrobials were most commonly prescribed group in FDC. Among antimicrobials amoxicillin-clavulanic acid was the most commonly prescribed rational FDC. Paracetamol and ibuprofen was the most commonly prescribed irrational FDC.

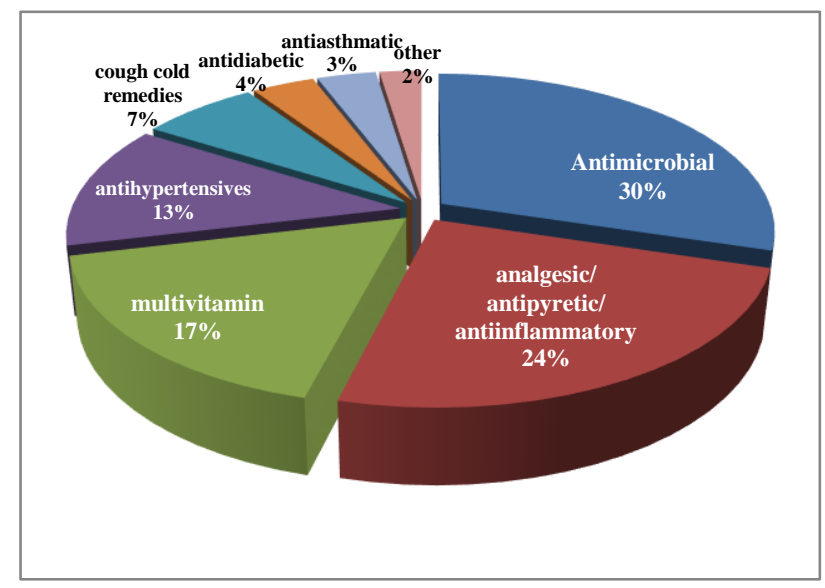

Figure 1: Practice of FDCs showing percentage of most commonly prescribed drug. 
Table 1: Knowledge regarding fixed drug combination.

\begin{tabular}{|c|c|c|}
\hline \multicolumn{2}{|l|}{ Questions } & Know (\%) \\
\hline \multicolumn{2}{|c|}{ Knowledge about FDC } & $76 \%$ \\
\hline \multicolumn{2}{|c|}{ Total number of drugs in NELM } & $56 \%$ \\
\hline \multicolumn{2}{|c|}{ FDC mentioned in WHO Essential List of Medicine } & $48 \%$ \\
\hline \multirow{5}{*}{$\begin{array}{l}\text { Advantages of } \\
\text { prescribing FDC }\end{array}$} & Improved patient compliance & $78 \%$ \\
\hline & Enhanced drug effect & $47 \%$ \\
\hline & Decreased side effect & $27 \%$ \\
\hline & Cheap & $17 \%$ \\
\hline & Patient demand & $4 \%$ \\
\hline \multirow{5}{*}{$\begin{array}{l}\text { Disadvantages of } \\
\text { prescribing FDC }\end{array}$} & Dose cannot be adjusted & $46 \%$ \\
\hline & More chances of ADR & $26 \%$ \\
\hline & Difficult to identify ADR & $43 \%$ \\
\hline & Polypharmacy & $11 \%$ \\
\hline & Costly & $7 \%$ \\
\hline \multirow{7}{*}{ Criteria of rationality } & Individual drug to have different mechanism of action & $23 \%$ \\
\hline & FDC to facilitate reduction in dose of individual compound or ADR & $19 \%$ \\
\hline & Each Active Pharmaceutical Ingredient (API) should be in NELM & $17 \%$ \\
\hline & Combination to have advantage of efficacy and safety over single compound & $14 \%$ \\
\hline & Dose and proportion to be appropriate for intended use & $11 \%$ \\
\hline & Pharmacokinetic parameters to be similar but no unfavourable interaction & $9 \%$ \\
\hline & Overall cost to be less than individual compound & $7 \%$ \\
\hline \multicolumn{2}{|c|}{ Knowledge about any banned FDC, if yes mention it. } & $58 \%$ \\
\hline \multirow{6}{*}{$\begin{array}{l}\text { Common sources of } \\
\text { information of FDC }\end{array}$} & CIIMS & $49 \%$ \\
\hline & Textbook & $38 \%$ \\
\hline & MR & $36 \%$ \\
\hline & CME & $29 \%$ \\
\hline & Journal & $17 \%$ \\
\hline & Internet & $15 \%$ \\
\hline
\end{tabular}

Table 2: Attitude regarding FDC.

\begin{tabular}{|ll|}
\hline Questions & Yes \\
\hline Preference to prescribe FDC & $58 \%$ \\
\hline Avoidance of use of irrational FDC & $92 \%$ \\
\hline $\begin{array}{l}\text { Rational FDC can cause serious Adverse Drug } \\
\text { Reaction (ADR) }\end{array}$ & $12 \%$ \\
\hline Irrational FDC can cause serious ADR & $89 \%$ \\
\hline $\begin{array}{l}\text { Rational FDC to be taught in detail to } \\
\text { healthcare professionals }\end{array}$ & $87 \%$ \\
\hline Reading of any article on rational FDC & $43 \%$ \\
\hline Directions regarding the use of FDC & $93 \%$ \\
\hline $\begin{array}{l}\text { Awareness of FDC is rational or not before } \\
\text { prescribing }\end{array}$ & $91 \%$ \\
\hline
\end{tabular}

\section{DISCUSSION}

Rational prescribing is not just the choice of correct drug for a disease but also the appropriateness of the whole therapeutic set up along with the follow up of the outcomes for which knowledge, attitude and skills are required. Knowledge is a set of understandings. It is also one's capacity for imagining, one's way of perceiving. Attitude includes three components: a) A cognitive or knowledge element

b) An affective or feeling element

c) A tendency to action. ${ }^{5}$

Practice refers to the ways in which they demonstrate their knowledge and attitude through their actions. ${ }^{6}$ Knowledge, attitude and practices are the important components for promoting rational prescribing of any drug or FDC. This improves patient compliance, wide spectrum coverage of the illness, decrease the duration of illness and finally eases the financial burden of the patient. Irrational FDC lead to ineffective and unsafe or over treatment, exacerbation or prolongation of illness, distress and harm to patient, increase the cost of treatment. ${ }^{7}$

Only twenty three percent of doctors are aware of rationality criteria. Amoxicillin-clavulanic acid was most commonly prescribed rational FDC for the infection of ear, sinus, respiratory, dermatology and urinary tract infection. Addition of clavulanic acid to amoxicillin re-establishes the activity of amoxicillin to $\beta$-lactamase producing resistant staph. aureus and also widen the spectrum of bacteria. $^{8}$ Ofloxacin-ornidazole was most commonly prescribed irrational FDC. It is commonly prescribed in diarrhoea and dysentery because it reduces number of 
watery stools, improves abdominal pain, gas/flatulence and nausea with excellent tolerability. FDCs of quinolones and nitroimidazoles (e.g. ciprofloxacin-tinidazole, ofloxacin- ornidazole) have not been recommended in any standard books, but were found to be heavily prescribed drugs in GI infections, pelvic inflammatory disease. ${ }^{9}$ This might be to cover up the diagnostic imprecision and the lack of laboratory facilities in the government setup. Such injudicious use of antibiotic FDCs can rapidly give rise to resistant strains of organisms and may lead to super infections.

A variety of irrational NSAIDs combinations are available. Paracetamol and ibuprofen was the most commonly prescribed irrational FDC. These combinations are often available as over the counter products (OTC). ${ }^{10}$

$24.25 \%$ of NSAIDs were prescribed among the total FDC. Moreover, these combinations are propagated by the media and the pharmaceutical companies with slogans like 'ibuprofen for pain and paracetamol for fever' and 'ibuprofen for peripheral action and paracetamol for central action'.

Various combinations of vitamins (17.25\%) are prescribed as nutritional supplements. However, a deficiency of all these vitamins may not be present in the given patient. Also the dose of different vitamins in the FDC may not be the same as recommended for prophylactic or therapeutic doses. Inappropriate use of FDCs may lead to several adverse reactions, over or under treatment.

The cough mixtures $(8.7 \%)$ contain expectorants, cough suppressants, antihistamines, sympathomimetics, alcohol and other CNS depressants with no peculiar rational basis. ${ }^{11}$ All ingredients may not be necessary at the same time. Moreover, the cough and cold remedies are available over the counter and if physician/pharmacists are not aware of the exact contents of the drug, it may lead to the incidence of haemorrhagic strokes in hypertensive patients which had happened with phenylpropanalamine containing cough cold remedies.

Lack of information related to indications and safety of drugs, poor communication between health professional and patient, lack of diagnostic facilities, uncertainty of diagnosis, defective drug supply system and ineffective drug regulation, promotional activities of pharmaceutical industries, influence from senior doctors may be the reasons for irrational use of drugs.

Fifty nine percent doctors are aware of banned FDCs. This can be minimized by forming strict rules by the governing bodies. In an attempt, Health ministry has banned 344 FDCs with other drugs for manufacturing and marketing in India. ${ }^{12}$ These include common cough syrup solution, analgesics and antimicrobial combinations.

The more stringent action should be taken for the prevention of use of irrational FDCs. The manufacturing, marketing and advertisement policy of the irrational FDCs and their easy availability over the counter has to be reviewed.

To prevent use of irrational FDCs at institution level the use of irrational FDCs should be discouraged and monitored regularly and stringently. Educational programmes like Continuous Medical Educations (CME) should be organised and conducted at every level UGs, PGs, interns, residents, faculties, pharmacist to create an awareness and basic knowledge of FDC. This will definitely improve the use of rational FDCs and ultimately minimize the loss to the society by decreasing morbidity, mortality, treatment failure, emergence of drug resistance and financial loss to community due to irrational use of FDCs.

Funding: No funding sources

Conflict of interest: None declared

Ethical approval: The study was approved by the Institutional Ethics Committee

\section{REFERENCES}

1. Sreedhar D, Subramanian G, Udupa N. Combination drugs: Are they rational? Curr Sci. 2006;91:406.

2. Essential drugs: $19^{\text {th }}$ updated WHO Model List; 2015. Available at: http://www.who.int/medicines/publications/essential medicines/en/. Accessed 8 May 2015.

3. Kastury N, Singh S, Ansari KU. An audit of prescription forrational use of fixed dose drug combinations. Indian J Pharmacol. 1999;31:367-9.

4. Panda J, Tiwari P, Uppal R. Evaluation of rationality of some FDC: focuson antihypertensive drugs. Indian J Pharm Sci. 2006;68(5):649-53.

5. Raina S. Assessment of knowledge, attitude, and practice in health care delivery. N Am J Med Sci. 2013;5:249-50.

6. Badran IG. Knowledge, attitude and practice the three pillars of excellence and wisdom: A place in the medical profession. Eastern Mediterranean Health Journal. 1995;1:8-16.

7. Shewade D, Pradhan S. Auditing of prescriptions in a government teaching hospital and four retail medical stores in Pondicherry. Indian $\mathbf{J}$ Pharmacol. 1998;30:408-10.

8. Petri WA. Penicillins, Cephalosporins, and Other $\beta$ lactam Antibiotics. In: Goodman and Gilman's the pharmacological basis of therapeutics. 12thed. Brunton LL, Lazo JS, Pasrker KL, editors, McGraw Hill; 2011:1477-1503.

9. Shewade D, Pradhan S. Auditing of prescriptions in a government teaching hospital and four retail medical stores in Pondicherry. Indian $\mathbf{J}$ Pharmacol. 1998;30:408-10.

10. Gulhati CM. Monthly index of medical specialities, India. MIMS India. 2005;25:81-94. 
11. Greenhalgh T. Drug prescription and self medication in India: Anexploratory survey Soc Sci Med. 1987;25:307-18.

12. Central drugs standard control organization. Drugs banned in India. 2012. Available at: http://cdsco.nic.in/html/drugsbanned. Accessed 12 June 2012.
Cite this article as: Admane $\mathrm{P}$, Hiware $\mathrm{S}$, Mahatme M, Dudhgaonkar S, Bargade M, Deshmukh S. Assessment of knowledge, attitude and practices among the residents and interns about rational fixed drug combinations in tertiary health care centre in Central India. Int J Basic Clin Pharmacol 2017;6:2172-6. 